\title{
The Environment and COVID-19 Transmission: A Perspective
}

\author{
Sokan-Adeaga Adewale Allen ${ }^{* 1}$, Sokan-Adeaga Micheal Ayodeji ${ }^{2}$, \\ Sokan-Adeaga Eniola Deborah ${ }^{3}$ \\ ${ }^{1}$ Department of Environmental Health Sciences, Faculty of Public Health, College of Medicine, \\ University of Ibadan, Ibadan, Nigeria \\ ${ }^{2}$ Department of Community Health and Primary Health Care, Faculty of Clinical Sciences, College of \\ Medicine, University of Lagos, Lagos, Nigeria \\ ${ }^{3}$ Department of Physiology, Faculty of Basic Medical Sciences, College of Medicine, Ladoke Akintola \\ University of Technology (LAUTECH), Ogbomosho, Oyo State, Nigeria \\ *Corresponding Author: Sokan-Adeaga Adewale Allen, Department of Environmental Health \\ Sciences, Faculty of Public Health, University of Ibadan, Ibadan, Nigeria
}

\begin{abstract}
Coronavirus disease 2019 (COVID-19) has become a severe public health threat worldwide. Despite the global spread, there is an observed aberration and skewness in the geographic/regional distribution of the disease, with a high preponderance of cases and mortality occurring in the temperate regions compared to the tropics. A plausible explanation for this discrepancy could be linked to variability in environmental factors. Hence, this review discusses succinctly the possible influences of geographic location, temperature/sunlight, relative humidity and building design on the rate of transmission of COVID-19. We postulate that elevated melatonin production in a hot climate, high temperature, adequate vitamin $D$ synthesis from sunlight exposure, high relative humidity and efficient ventilation due to housing design confers innate immunity and adaptive advantage to COVID-19 transmission for populations in the tropics over those in the temperate regions. Hence, we recommend that control studies taking into congnizance the relationship between environment and disease be prioritized. Such studies are important for predicting viral disease spread, in particular if this leads to pandemics like in the case of COVID-19, to aid decisions in public health policies at the global level.
\end{abstract}

Keywords: COVID-19, SARS-CoV-2, Tropics, Temperate, Environmental Factors, Transmission.

\section{INTRODUCTION}

It is a fact that the morbidity and mortality due to nCovid-19 are rising daily with its attendant consequences on human life, economic and political affairs globally. Several pieces of researches and efforts being made by clinicians, scientists and international agencies to develop a vaccine to combat this deadly scourge still remain futility [1]. Currently, a lot of developed and developing nations are forced to relax the prolonged total lockdown initially imposed on their citizenry and economic activities despite the astronomically daily increase in the number of COVID-19 cases globally. The reason for this action, might not be far-fetched from the economic relapsed presently witness by most countries around the globe.

Just barely over a semester, COVID-19 pandemic caused by severe acute respiratory syndrome coronavirus 2 (SARS-CoV-2) emerged from the city of Wuhan, a Hubei province in China and spread sporadically to over 213 countries around the globe and two international conveyances. COVID-19 infection is an airborne disease that could result in severe respiratory illness, similar to the severe acute respiratory syndrome coronavirus (SARS-CoV) $[2,3]$. The incidence of illness and infectivity of any virus that is conveyed by the airborne route in an indoor and ambient environment is dependent upon numerous factors. These include population density, temperature, exposure to Ultraviolet (UV) ray or antiviral chemicals, humidity, susceptibles number, exposure duration, ventilation rate, settling rate of an infectious particle, presence of lipid or non-lipid envelope around the virus, number of infected people producing contaminated aerosols, the presence of encompassing organic material, antibiotic resistance or antiviral therapy resistance by microbes, form and level of invasive procedures, spatial considerations such as seating or sleeping arrangements and 
contact with a carrier, pathogens persistence within hosts, immuno-epidemiology, evolution and transmission of resistance and host genetic factors role [4].

At the present, the global total number of confirmed cases is estimated at 7,939,988 with 433,904 deaths, and 4,078,668 recovered from the coronavirus COVID-19 outbreaks to date, June 14, 2020, 17:41 GMT (source: https:// www. worldometers. info/coronavirus). Despite the global spread, there is an empirical aberration and skewness in the geographic/regional distribution of the disease, with a high preponderance of cases and mortality witnessed by the western nations and countries in temperate regions of the world. The most probable explanation or hypothesis for this discrepancy in the epidemiologic distribution of the pandemic between the temperate and tropical countries of the world is variability in environmental factors. However, this lacuna has been underestimated or overlooked by key players (scientists, policymakers, international agencies etc.) in the COVID-19 battle. It is therefore reasonable that this review discusses succinctly the possible influences of various environmental parameters vis geographic location, temperature/sunlight, relative humidity and building design on the rate of transmission of COVID-19.

\section{INFLUENCE OF ENVIRONMENTAL VARIABLES ON COVID-19 TRANSMISSION Geographic Location}

It has come to the erudition of humans that climatic variables influence epidemic diseases Table1. Case comparison of COVID-19 by regions as at 10:19am CEST, 13 June, 2020 (Source: WHO) [15]

\begin{tabular}{|c|c|}
\hline WHO Regions & Total Confirmed Cases \\
\hline Americas & $3,638,525$ \\
\hline Europe & $2,358,953$ \\
\hline Eastern Mediterranean & 737,641 \\
\hline South-East Asia & 439,348 \\
\hline Western Pacific & 196,715 \\
\hline Africa & 161,254 \\
\hline
\end{tabular}

In this sub-section, we shall limit our discussion to the influence of geographic location in melatonin production and its role in body defense mechanism; and discuss the other two points in subsequent sub-headings. Melatonin (MLT) is an amine hormone produced primarily by the pineal gland. The physiological function of MLT is mainly to control the circadian rhythm. There is also conflicting evidence about the action of melatonin on mammalian epidermal melanocytes [16]. Melanocytes are involved in the production of melanin, which is long before the role of infectious agents was unraveled, late in the nineteenth century. Roman aristocrats retreated to hill resorts every summer to prevent malaria, and also south Asians realized early that, in high summer, strongly curried foods were less likely to cause diarrhea [5]. Climatic conditions affect microbial viability and virulence; and consequently microbes (virus, bacteria, fungi, parasites etc.) show variability in their pathogenicity from one region to the other.

Several workers described investigations of the possible relationships between climate and respiratory viruses such as SARS, influenza, and respiratory syncytial virus (RSV) which causes mild, cold-like symptoms in adults and older healthy juveniles [6-8]. Several studies have established variability in the vital role play by latitude in viral conveyance and seasonality [911]. As evident in Table 1, temperate regions have a higher number of cases than tropical regions Thus, it can be surmised that the harsh conditions in the tropics have an inimical effect on the survival and transmission rate of SARS$\mathrm{CoV}-2$. Viral transmission as a consequence of seasonal variation has been ascribed to at least three factors. Firstly, Dowell [12] opine extrinsically driven cycles in host resistance to infection may be linked to seasonal fluctuations in melatonin. Secondly, Cannell et al. [13] suggest that circulating vitamin D metabolites or a deficiency of vitamin D may compromise human immunity. Thirdly, Shaman and Kohn [14] propose external discrepancies such as ambient temperature and relative humidity $(\mathrm{RH})$ in viral survival. responsible for the pigmentation of the skin; with pigmentation greatest in the tropics and reduce in temperate zones [17]. Thus it is expected that melatonin production will be higher among those in the tropics compare to those in the temperate. Also, darkness promotes MLT production while light (fluorescent source) decreases it. Most countries in the tropics especially Africans do not have access to uninterrupted electricity hence spent most of their time in the dark. This might be a contributing factor to the high production of 
melatonin among Africans compare to their counterparts in the western worlds.

Recent studies have demonstrated that MLT could influence the immune system through several ways to regulate the function of the immune system. In infectious diseases, MLT can regulate the number of immune cells and the expression of cytokines. Moreover, MLT may enhance the function of the immune system by reducing the secretion of inflammatory factors, down-regulating the adhesion of leukocytes and anti-oxidation, which may reduce the pathology caused by inflammation damage [18]. Hence, we postulate that, MLT could play a role against pathogens infection by directly inhibiting the replication and proliferation of pathogens. Thus, it is reasonable to surmise that higher melatonin production among people in the tropics (especially Africans, Latinos, and some Asians) confer natural immunity on them against COVID-19 disease. Therefore, MLT may be considered as a novel target and a new method for the clinical treatment of infectious diseases.

\section{Temperature/Sunlight}

Some pundits believe that temperature is one of the vital parameters influencing virus survival, as it can impact the virus RNA or DNA and the viral proteins state. Viruses having DNA has its nuclei composition exhibit greater stability than RNA viruses. Generally, virus survival is inversely proportional to temperature. Maintaining temperatures greater than $60^{\circ} \mathrm{C}$ $\left(140^{\circ} \mathrm{F}\right)$ above 1 hour will usually inactivate most viruses, though this can differ depending on the presence of organic material (e.g. feces, saliva, blood, mucus, etc.) that may encircle the exhaled viral particles and insulate the virus against extreme environmental variations. Elevated temperatures for a shorter duration can be effective in viral inactivation [8].

Another plausible explanation for the discrepancy in the number of cases and rate of transmission of COVID-19 in the tropics and temperate region [Table 2] is the temperature difference. The tropics are characterized by high temperature (hot weather) with an annual mean temperature between $70^{\circ} \mathrm{F}$ to $85^{\circ} \mathrm{F}\left(21^{\circ} \mathrm{C}\right.$ to $30^{\circ} \mathrm{C}$ ). Temperate climates of the Earth are characterized by relatively moderate mean annual temperatures, with average monthly temperatures above $10^{\circ} \mathrm{C}$ in their warmest months and above $-3^{\circ} \mathrm{C}$ in their colder months [19]. The SARS-CoV-2 and SARS-CoV genomes show strong identity; and the transmission of SARS-CoV is temperaturedependent. Thus, SARS-CoV-2 is suspected, like other coronaviruses, to have a weatherdependent virulence $[20,21]$. The variations in weather singly would not necessarily decline numbers of confirmed cases during the whole epidemic, but warm and humid weather could make SARS-CoV-2 less vulnerable and less stable, instigating a break in the transmission chain, and hence decreasing the contagious potency of the disease [22].

Therefore, we postulate that SARS-CoV-2 being an RNA virus has its proteins being easily denatured by high temperature and ultraviolet (UV) ray, thus consequently affect its viability and survival in the tropics than in the temperate. Based on the aforementioned proposition, we deduce that these factors (high temperature and UV light) might be responsible for its low transmission rate in the tropics. However, high numbers of confirmed cases in some tropical regions such as Southern America (Brazil, Peru); Mexico, Dominican Republic etc. might be attributed to poor public health measures such as overcrowding, environmental pollution, poor housing conditions, nutritional disorder etc., which exacerbate the vulnerability of the subjects to the disease. We also predict that number of COVID-19 cases will reduce in the summer and fall compared to the winter and spring seasons in countries with temperate climates. This is because that hot climate improve the efficiency of "ciliary" cells, these are tiny hair protecting the upper respiratory airway (from nose to bronchioles) [23].

Table2. Comparison of the total number of cases and deaths among some temperate and tropical countries of the world to date June 14, 2020 (17:41GMT). Source: https://www.worldometers.info/coronavirus/\#countries

\begin{tabular}{|c|c|c|c|c|c|c|c|}
\hline S/N & $\begin{array}{c}\text { Temperate } \\
\text { Countries }\end{array}$ & $\begin{array}{c}\text { Total } \\
\text { Cases }\end{array}$ & $\begin{array}{c}\text { Total } \\
\text { Death }\end{array}$ & S/N & Tropical Countries & $\begin{array}{c}\text { Total } \\
\text { Cases }\end{array}$ & $\begin{array}{c}\text { Total } \\
\text { Death }\end{array}$ \\
\hline $\mathbf{1}$ & USA & $2,151,730$ & 117,649 & $\mathbf{1}$ & Brazil & 852,758 & 42,837 \\
\hline $\mathbf{2}$ & Russia & 528,964 & 6,948 & $\mathbf{2}$ & Peru & 225,132 & 6,498 \\
\hline $\mathbf{3}$ & India & 332,739 & 9,514 & $\mathbf{3}$ & Mexico & 142,690 & 16,872 \\
\hline $\mathbf{4}$ & United Kingdom & 295,889 & 41,698 & $\mathbf{4}$ & Dominican Republic & 22,962 & 592 \\
\hline $\mathbf{5}$ & Spain & 290,685 & 27,136 & $\mathbf{5}$ & Nigeria & 15,682 & 407 \\
\hline $\mathbf{6}$ & Italy & 236,989 & 34,345 & $\mathbf{6}$ & Haiti & 4,165 & 70 \\
\hline $\mathbf{7}$ & Iran & 187,427 & 8,837 & $\mathbf{7}$ & Kenya & 3,594 & 103 \\
\hline
\end{tabular}




\begin{tabular}{|c|c|c|c|c|c|c|c|}
\hline $\mathbf{8}$ & Turkey & 178,239 & 4,807 & $\mathbf{8}$ & Gabon & 3,463 & 23 \\
\hline $\mathbf{9}$ & France & 156,813 & 29,398 & $\mathbf{9}$ & Nicaragua & 1,464 & 55 \\
\hline $\mathbf{1 0}$ & Canada & 98,735 & 8,146 & $\mathbf{1 0}$ & Myanmar & 261 & 6 \\
\hline
\end{tabular}

Another effect is the high production of vitamin $\mathrm{D}$ by exposure to UV light in the tropics region due to high sunlight intensity. Vitamin D is primarily obtained through exposure to sunlight, and thus, the modern lifestyle in many western countries has resulted in many people being perpetually deficient. Vitamin D synthesis decreases from age 70yrs and above of life, due to a decline in solar exposure and cutaneous synthesis [24]. It is low among the westernized population, $75 \%$ of them being severely vitamin $\mathrm{D}$ deficient (serum $25(\mathrm{OH}) \mathrm{D}<25 \mathrm{nmol} / \mathrm{L}$ ) [25]. Vitamin D helps to bolster the immune system which inhibits infection and also acts as a powerful anti-inflammatory agent. Vitamin D may help to modulate the response of white blood cells to the virus, preventing them from secreting excessive inflammatory cytokines. Also, it is a fact that high temperature/hot weather increase retinoic acid (vitamin A) metabolism in the body to retinol (performed vitamin A) which is the active and utilizable form in the body. Vitamin A helps to regulate the immune system, acts as an antioxidant and promotes the growth and health of body cells and tissues, particularly in the lungs. The ACE2 gene encodes the angiotensinconverting enzyme-2, has been proved to be the receptor for both the SARS-coronavirus (SARS$\mathrm{CoV}$ ) and the human respiratory coronavirus NL63. New researches and analyses show that ACE2 (angiotensin-converting enzyme) could be the host receptor for the novel coronavirus 2019nCoV/SARS-CoV-2 [26, 27]. Calcitriol $(1,25-$ dihydroxyvitamin $D_{3}$ ) exerted significant impact on the Renin-Angiotensin System, by suppressing the renin gene expression and thereby impeding the ACE2 receptor of COVID-19 and it also modulates macrophages' response, preventing them from secreting excessive inflammatory cytokines and chemokines [28-30].

Thus we postulate that high production of vitamin $\mathrm{D}$ and increase rate of retinoic acid (vitamin A) metabolism among Africans confers them with innate immunity advantage against COVID-19 compared to their counterparts in Europe and Americas, who are usually vitamin $\mathrm{D}$ deficient and have lesser rate of vitamin A metabolism, hence serving as a contributing factor to the low transmission and mortality rate of the disease in the tropics. This assertion is corroborated by other studies, which depicted an inverse correlation between serum 25- hydroxyvitamin D (25-h D) levels and upper respiratory tract infection (URTI) [13,31,32]. Also, the Southern European countries have declined levels of vitamin $\mathrm{D}$ due to low exposure (prefer the shade in strong sun) [24] and also as skin pigmentation reduces vitamin D synthesis [33]. This might be responsible for the high number of cases and mortality witnessed in countries such as Spain and Italy, as shown in Table 2; with the aging people being the highest risk group [25]. Also, it is important to note that it is difficult to obtain sufficient quantities of this micronutrient through diet alone. Exposure to sunlight remains the primary source of vitamin D production from provitamin in the body. This assertion is validated by the high mortality episode of black people in America from COVID-19 due to low vitamin D deficiency; since dark-skinned people usually need more sunlight exposure compared to lightskinned people to generate a commensurate quantity of vitamin D. However, it is imperative to state that public health measures, individual lifestyle, age distribution, and presence of underlying ailments play a key role in this innate defense mechanism.

\section{Relative Humidity}

Numerous researchers, including Shephard and Shek [34], Schaffer et al. [35], Harper [36], and Hemmes et al., [37] proposed three potential mechanisms to elucidate the observed impact of relative humidity $(\mathrm{RH})$ on microbial transmission. Firstly, RH may act at the host level. Breathing dry air could lead to the desiccation of the nasal mucosal, resulting in epithelial damage and/or declined mucociliary clearance, which consequently increases the host susceptibility to respiratory virus infections. The mucociliary clearance apparatus is an important defense mechanism for clearing the lung of invasive particulate matter [38]. Microbial (viral or bacterial) infections and pollutants may cause derangement of mucociliary clearance [39] and likewise influence the innate rheological features vis the adhesiveness of nasal mucus and/or slowing of ciliary beating according to Salah et al. [40]. The second mechanism is that RH may act at the viral particle level. The stability of influenza virions in an aerosol has been reported to vary significantly through a range of $\mathrm{RH}$. The third mechanism is when RH acts at the level of the 
respiratory droplet. At low $\mathrm{RH}$, water evaporation from exhaled bio-aerosols occurs rapidly, resulting in droplet nuclei formation. Conversely, at high $\mathrm{RH}$, small respiratory droplets adhere to water, enlarge in size and precipitate quickly out of the air. Similar to most theories of aerosol transmission, a conglomeration of these factors is probably involved.

Studies have investigated the survival of the artificially aerosolized virus in a wide range of RH from $15 \%$ to $90 \%$ with results showing the extreme discrepancy in infectivity and survival. It is widely acknowledged that viruses with lipid envelopes such as influenza, RSV, and herpes viruses, are more stable at lower $\mathrm{RH}$ while other studies demonstrate that non-lipid enveloped viruses such as respiratory adenoviruses and rhinoviruses survive longer at higher RHs [4144]. Human coronaviruses are enveloped viruses and usually have a low survival rate in high humidity. Thus, it will be reasonable to opine that SARS-CoV-2 the causative agent of COVID-19 is usually inactivated in tropical climate due to its high humidity and consequently exhibit low survival rate. This statement aligns with the experimental finding of Casanova et al. [45]. The authors study the relationship between inactivation of SARS-CoV and $\mathrm{RH}$, and observed that the survival rate of the virus was greater only at low relative humidity. Our proposition is also strengthened by the observed high transmission rate among air travelers who were responsible for the global spread of the disease at the early stage of the pandemic. The relative humidity in airplanes particularly during the in-flight time usually ranges from $3 \%$ to $15 \%$. Hence one can conclude that this extremely low relative humidity and closed environment contribute immensely to the disease contagion. In addition, breathing at low humidity leads to a loss in mucosal water which consequently influences the rate of mucosal clearance.

\section{Building Structure - Ventilation}

Room airflow is dependent on an agglomeration of air movements initiated by temperature variations, ventilation, and mobile bodies and facilities. These ambiguous air movements make the path and suspension time of an infectious substance very arduous to predict once it migrates from the infectious host. The primary origins of infectious airborne pathogens in enclosed vicinities are respiratory droplets produced when an infected person coughs, sneezes, breathes, or talks. An extensive literature review depicts that there have been very limited studies on the association between exhalation flows and room ventilation systems. A recent systematic review conducted by $\mathrm{Li}$ et al. [46] illustrated that a poor ventilation system escalates the transmission of airborne disease, while an efficient ventilation system can assist in mitigating the spread of infectious particles and subsequently reduce disease transmission. Also, a study by Drinka et al. [47] of a long term care facility reported relationship between influenza infection and ventilation system design in different monuments. Generally, the more the percentage of ambient air circulating in the buildings, the decline in the proportion of patients infected.

Most buildings in the western world are tightly sealed energy-conserving buildings with reduced fresh air ventilation rates compared with buildings in the tropics which are usually designed for adequate ventilation because of warm weather. In most settings where ventilation is copious, the transmission of airborne disease such as COVID-19 is greatly impaired vis-à-vis buildings with a low ventilation system which exacerbate indoor airborne pathogen transmission. Hence, we postulate that the discrepancy in ventilation rate, arising from variations in building design in the tropics and temperate regions; possibly contributes to the high transmission rate of the pandemic in the latter. However, it is essential to clarify that overcrowding even in a wellventilated room can predispose occupants to airborne infection. This might be responsible for some high number of cases witnessed in some tropical countries etc.

\section{CONCLUSiONS}

There is no established proof that any single parameter, whether it be a specific temperature, relative humidity, or geographic location can be universally applied to the diverse infectious viruses to decrease airborne or contact transmission, but there is a convincing fact in the literature that viruses and other infectious agents survival depends partially on environmental conditions.

From the foregoing discussion, it can be concluded that variations in environmental factors such as geographic location, climatic factors or housing design offer a plausible explanation for the discrepancy in the transmission and mortality rate of COVID-19 pandemic experienced in the tropics (especially Africa) and temperate (Europe and Americas) 
regions. It is worthwhile to note that numerous airborne infectious organisms and even strains of the same pathogen will have diverse conditions under which they may be optimally suppressed or even annihilated. Hence, we recommend that control studies taking into cognizance the relationship between environment and disease be prioritized. Such studies are consequential in the prediction of viral disease transmission, particularly if this results in pandemics like in the case of COVID19 , in order to aid decisions in public health policies at the global level.

\section{ACKNOWLEDGEMENTS}

The authors sincerely acknowledge the efforts of all those who are working tirelessly to find a lasting solution to the COVID-19 pandemic.

\section{REFERENCES}

[1] Sokan-Adeaga AA, Sokan-Adeaga MA, SokanAdeaga ED, Oparazi AN. "The Deadly Scourge Call COVID-19: Will Mankind Find a Panacea to this Pandemic?". Acta Scient Med Sciences 2020; 4(6):70-78.

[2] Huang C, Wang Y, Li X, Ren L, Zhao J, Hu Y, et al. Clinical features of patients infected with 2019 novel coronavirus in Wuhan, China. Lancet. 2020 Feb; 395(10223): 497-506. doi: 10.1016/S0140-6736(20)30183-5.

[3] Xu Z, Shi L, Wang Y, Zhang J, Huang L, Zhang $C$, et al. Pathological findings of COVID-19 associated with acute respiratory distress syndrome. Lancet Respir. Med. 2020 Apr; 8(4):420-422. doi: 10.1016/S22132600(20)30076-X.

[4] Farhad Memarzadeh. Literature review of the effect of temperature and humidity on viruses. ASHRAE Transaction. 2012 Jan; 118.

[5] World Health Organisation. Climate change and human health. Geneve: WHO; 2020 May 9. Available in https://www.who.int/ global change/summary/en/index5.html. 2020.

[6] Thompson WW, Shay DK, Weintraub E, Brammer L, Cox N, Anderson LJ, et al. Mortality associated with influenza and respiratory syncytial virus in the United States. JAMA. 2003 Jan; 289(2):179-86. doi: 10.1001/ jama.289.2.179.

[7] Thompson WW, Comanor L, Shay DK. Epidemiology of seasonal influenza: Use of surveillance data and statistical models to estimate the burden of disease. J. Infect Dis. 2006 Nov; 194(Suppl 2):S82-S91.

[8] Tang JW. The effect of environmental parameters on the survival of airborne infectious agents. J. R. Soc. Interface 2009 Dec; 6 (Suppl 6):S737-S746. doi: 10.1098/rsif. 2009.0227.focus.
[9] Viboud C, Alonso WJ, Simonsen L. Influenza in tropical regions. PLoS Med. 2006 Apr; 3(4):e89. doi: 10.1371/journal.pmed.0030089

[10] Tang JW, Ngai KLK, Lam WY, Chan PKS. Seasonality of influenza A (H3N2) virus: A Hong Kong perspective (1997-2006). PLoS ONE. 2008 Jul; 3(7):e2768. doi: 10.1371/ journal.pone.0002768

[11] Tang JW, Lai, FY, Wong F, Hon KL. Incidence of common respiratory viral infections related to climate factors in hospitalized children in Hong Kong. Epidemiol. Infect. 2010 Feb; 138 (2):226-35. doi:10.1017/S0950268809990410.

[12] Dowell SF. Seasonal variation in host susceptibility and cycles of certain infectious diseases. Emerg Infect. Dis. 2001 May-Jun; 7(3): 369-374. doi: 10.3201/eid0703.010301

[13] Cannell JJ, Vieth R, Umhau, JC, Holick, MF, Grant WB, Madronich S, Garland CF, Giovannucci E. Epidemic influenza and vitamin D. Epidemiology and Infection. 2006 Dez; 134(6):1129-40. doi: 10.1017/S09502688 06007175.

[14] Shaman J, Kohn M. Absolute humidity modulates influenza survival, transmission, and seasonality. Proc. Natl Acad. Sci. 2009 Mar; 106(9):3243-8. doi:https://doi.org/ 10.1073/ pn as.0806852106.

[15] World Health Organisation. WHO Coronavirus Disease (COVID-19) Dashboard. Geneve: WHO; 2020.

[16] Richard DA. The therapeutic effect of melatonin on canine melanosis. J. Invest Dermatol. 1965 Jan; 44:6 -13. doi: 10.1038/ jid.1965.3.

[17] Fleure HJ. The distribution of types of skin colour. Geogr Rev. 1945; 35:593 - 95.

[18] Yan M, Kang T, Chunmei Z, Yusi Z, Yun Z, Boquan $J$, et al. Advances in the Role of Melatonin in Infectious Diseases: A Review. Chinese Journal of Cellular and Molecular Immunology. 2019 Jun; 35(6):563-568.

[19] Society, National Geographic. "Köppen Climate Classification System". National Geographic Society. Retrieved 2020-04-02. 2019 https:// www.nationalgeographic.org/encyclopedia/kop pen-climate-classification-system/

[20] Ahmed SF, Quadeer, AA, McKay MR. Preliminary Identification of Potential Vaccine Targets for the COVID-19 Coronavirus (SARSCoV-2) Based on SARS-CoV Immunological Studies. Viruses 2020 Mar; 12(3):254.

[21] Lin K, Fong DYT, Zhu B, Karlberg J. Environmental Factors on the SARS Epidemic: Air Temperature, Passage of Time and Multiplicative Effect of Hospital Infection. Epidemiol. Infect. 2006 Apr; 134(2):223-230. doi: 10.1017/S0950268805005054

[22] Chan KH, Peiris JS, Lam SY, Poon LL, Yuen KY, Seto WH. The Effects of Temperature and 
Relative Humidity on the Viability of the SARS Coronavirus. Adv. Virol. 2011;2011:734690. doi: $10.1155 / 2011 / 734690$

[23] Berbari NF, O'Connor AK, Haycraft CJ, Yoder BK. The primary cilium as a complex signaling center. Curr Biol. 2009 Jul; 19(13):R526-35. doi: 10.1016/j.cub.2009.05.025.

[24] Adami S, Bertoldo F, Braga V, Fracassi E, Gatti D, Gandolini G, et al. 25-Hydroxy vitamin $\mathrm{D}$ levels in healthy premenopausal wome: association with bone turnover markers and bone mineral density. Bone 2009 Sep; 45(3):423-426. doi: https://doi.org/10.1016/j. bone. 2009.05.012

[25] Lips P, Cashman K, Lamberg-Allardt C, Bischoff-Ferrari HA, Obermayer-Pietsch B, Bianchi ML, et al. Current vitamin D status in European and Middle East countries and strategies to prevent vitamin D deficiency: a position statement of the European Calcified Tissue Society. Eur J Endocrinol. 2019 Apr; 180(4):23-54. doi: 10.1530/EJE-18-0736.

[26] Zhou P, Yang K-L, Wang X-G, Hu B, Zhang L, Zhang $\mathrm{W}$, et al. A pneumonia outbreak associated with a new coronavirus of probable bat origin. Nature 2020 Mar; 579(7798): 270273. doi: https://doi.org/10.1038/s41586-0202012-7 (2020).

[27] Lu, R, Zhao X, Li J, Niu P, Yang B, Wu H, et al. Genomic characterisation and epidemiology of 2019 novel coronavirus: implications for virus origins and receptor binding. Lancet. 2020 Feb; 395(10224): 565-574. doi: https:// doi. org/10.1016/S0140-6736(20)30251-8(2020).

[28] Cui C, Xu P, Li G, Qiai Y, Han W, Geng C, et al. Vitamin D receptor activation regulates microglia polarization and oxidative stress in spontaneously hypertensive rats and angiotensin II-exposed microglial cells: role of renin-angiotensin system. Redox Biol. 2019 Sep; 26:101295. doi: https://doi.org/10. 1016/ j.redox.2019.101295

[29] Helming L, Böse J, Ehrchen J, Schiebe S, Frahm T, Geffers R, et al. 1-alpha,25Dihydroxyvitamin $\mathrm{D}_{3}$ is a potent suppressor of interferon gamma-mediated macrophage activation. Blood 2005 Dec; 106(13):43514358. doi: 10.1182/blood-2005-03-1029.

[30] Sahar A, Arif A, Ali N. The effects of vitamin $\mathrm{D}$ on the renin-angiotensin system. $J$ Nephropathol. 2014 Apr; 3(2):41-43. doi: 10. 12860/jnp.2014.09

[31] Cannell, JJ, Zasloff, M, Garland CF, Scragg R, Giovannucci E. On the epidemiology of influenza. Virol J. 2008 Feb; 5:29. doi: 10.1186/1743-422X-5-29.

[32] Cannell JJ, Zasloff M, Garland CF, Scragg R, Giovannucci E. On the epidemiology of influenza: Reply to Radonovich et al. Virol J. 2009Aug;6:121.doi:10.1186/1743-422X-6-121.
[33] Matsuoka LY, Wortsman J, Haddad JG, Kolm $\mathrm{P}$, Hollis BW. Racial pigmentation and the cutaneous synthesis of vitamin D. Arch Dermatol. 1991 Apr; 127(4):536-538.

[34] Shephard RJ, Shek PN. Cold exposure and immune function. Can J Physiol Pharmacol. 1998 Sep; 76(9):828-36. doi: 10.1139/cjpp-769-828.

[35] Schaffer FL, Soergel ME, Straube DC. Survival of airborne influenza virus: Effects of propagating host, relative humidity, and composition of spray fluids. Arch Virol. 1976;51:263-73. doi: 10.1007/BF01317930.

[36] Harper GJ. Airborne micro-organisms: Survival tests with four viruses. J Hyg. 1961 Dec; 59 (4):479-48.doi:10.1017/s002217240003917 6.

[37] Hemmes JH, Winkler KC, Kool SM. Virus survival as a seasonal factor in influenza and poliomyelitis. Nature. 1960 Oct; 188: 430-431.

[38] Bennett WD. Effect of $\beta$-adrenergic agonists on mucociliary clearance. J Allergy Clin. Immunol. 2002 Dec; 110(6 Suppl):S291-S297. doi: 10.1067/mai.2002.129704.

[39] Mubareka S, Lowen AC, Steel J, Coates AL, García-Sastre A, Palese P. Transmission of influenza virus via aerosols and fomites in the guinea pig model. J Infect Dis. 2009 Mar; 199(6):858-65. doi: 10.1086/597073.

[40] Salah B, Xuan ATD, Fouilladieu JL, Lockhart A, Regnard J. 1988. Nasal mucociliary transport in healthy subjects is slower when breathing dry air. Eur Respir J. 1988 Oct; 1(9):852-55.

[41] Hermann J, Hoff S, Muñoz-Zanzi C, Yoon k-J, Roof M, Burkhardt A, et al. Effect of temperature and $\mathrm{RH}$ on the stability of infectious porcine reproductive and respiratory syndrome virus in aerosols. Vet. Res. 2007 JanFeb; 38(1): 81-93.doi:10.1051/vetres:200604 4.

[42] Arundel AV, Sterling EM, Biggin JH, Sterling TD. Indirect Health Effect of Relative Humidity in Indoor Environments. Environ Health Perspect. 1986 Mar;65:351-61. doi: 10.1289/ehp.8665351.

[43] Cox CS. Airborne bacteria and viruses. Sci Prog. 1989; 73(292, Pt 4):469-99.

[44] Collier L, Balows A, Sussman M. Topley and Wilson's Microbiology and Microbial Infections. 9th ed. London, UK: Arnold, Oxford University Press; 1998. P. 339-350.

[45] Casanova LM, Jeon S, Rutala WA, Weber DJ, Sobsey MD. Effects of air temperature and relative humidity on coronavirus survival on surfaces. Appl Environ Microbiol, 2010 May; 76(9): 2712-2717. doi: https://doi.org/ 10.1128/ AEM.02291-09 
The Environment and COVID-19 Transmission: A Perspective

[46] Li Y, Leung G, Tang JW, Yang X, Chao CYH, Lin JZ, et al. Role of ventilation in airborne transmission of infectious agents in the built environment - A multidisciplinary systematic review. Indoor Air. 2007 Feb; 17(1):2-18. doi: 10.1111/j.1600-0668.2006.00445.x.
[47] Drinka PJ, Gravenstein S, Krause P, Nest L, Dissing M, Shult P. Reintroduction of Influenza A to a nursing building. Infect Control Hosp Epidemiol. 2000 Nov; 21(11):732-5. doi: $10.1086 / 501715$.

Citation: Sokan-Adeaga Adewale Allen et al, "The Environment and COVID-19 Transmission: A Perspective”, International Journal of Research Studies in Medical and Health Sciences. 2020; 5(7): 12-19.

Copyright: (C) 2020 Sokan-Adeaga Adewale Allen et al, This is an open-access article distributed under the terms of the Creative Commons Attribution License, which permits unrestricted use, distribution, and reproduction in any medium, provided the original author and source are credited. 